\author{
Supporting Information for \\ Electrochemical Study on High Electrochemical Double Layer Capacitance \\ of Ordered Porous Carbons with both Meso-/Macropores and Micropores \\ Hirotoshi Yamada, ${ }^{a}$ Haruka Nakamura, ${ }^{a}$ Fumihiro Nakahara,${ }^{b}$ Isamu Moriguchi, ${ }^{a}$ Tetsuichi Kudo ${ }^{c}$ \\ ${ }^{a}$ Faculty of Engineering, Nagasaki University \\ ${ }^{\mathrm{b}}$ Graduate School of Science and Technology, Nagasaki University \\ ${ }^{\mathrm{c}}$ Joint Research Center, Nagasaki University \\ 1-14, Bunkyo-machi, Nagasaki, 852-8521, Japan
}

\title{
X-ray photoelectron spectroscopy (XPS)
}

The surface of porous carbons was investigated by XPS on an ESCA-850M (Shimadzu Corp.) with an $\operatorname{MgK} \alpha$ irradiation. Detailed analysis was carried out by fitting the spectra. The binding energy was calibrated using a graphitic peak of $\mathrm{C} 1 \mathrm{~s}$ at $284.6 \mathrm{eV}$. Each curve was fitted using a non-linear least-squares methods with a Gaussian-Lorentzian function or Gaussian function, and backgrounds were approximated by Shirly's method.

Wide range spectra revealed that only $\mathrm{C}$ and $\mathrm{O}$ existed on carbon surfaces. Figures $\mathrm{S} 1(\mathrm{a}, \mathrm{b})$ demonstrate spectra of $\mathrm{C} 1 \mathrm{~s}$ and $\mathrm{O} 1 \mathrm{~s}$ ranges of porous carbons, C[45]-5. The $\mathrm{C} 1 \mathrm{~s}$ spectrum were fitted with four peaks, $\mathrm{C}_{\mathrm{I}}, \mathrm{C}_{\mathrm{II}}, \mathrm{C}_{\mathrm{IIII}}$, and $\mathrm{C}_{\mathrm{IV}}$, which are ascribed to graphitic carbon (284.6 eV), C-OH (286.1 $\mathrm{eV}), \mathrm{C}=\mathrm{O}(288.2 \mathrm{eV})$ and $\mathrm{COOH} / \mathrm{COOR}(288.8 \mathrm{eV})$, respectively. ${ }^{\mathrm{S} 1}$ The O1s spectrum was separated into two peaks: $\mathrm{O}_{\mathrm{I}}(532.5 \mathrm{eV})$ and $\mathrm{O}_{\mathrm{II}}(534.4 \mathrm{eV})$. With respect to the $\mathrm{C} 1 \mathrm{~s}$ peak, the fitting results indicated that hydroxyl groups $\left(\mathrm{C}_{\mathrm{II}}\right)$ and carboxyl groups $\left(\mathrm{C}_{\mathrm{IV}}\right)$ are dominant on the carbon surfaces, while carbonyl groups were supposed to be minor. For the O1s peak, $\mathrm{O}_{\mathrm{I}}$ and $\mathrm{O}_{\mathrm{II}}$ are ascribable to $\mathrm{COH}$ and $\mathrm{COOH}$, respectively. Even the carbonized temperature was raised from $800^{\circ} \mathrm{C}$ to $1000^{\circ} \mathrm{C}$, any significant change was not observed.
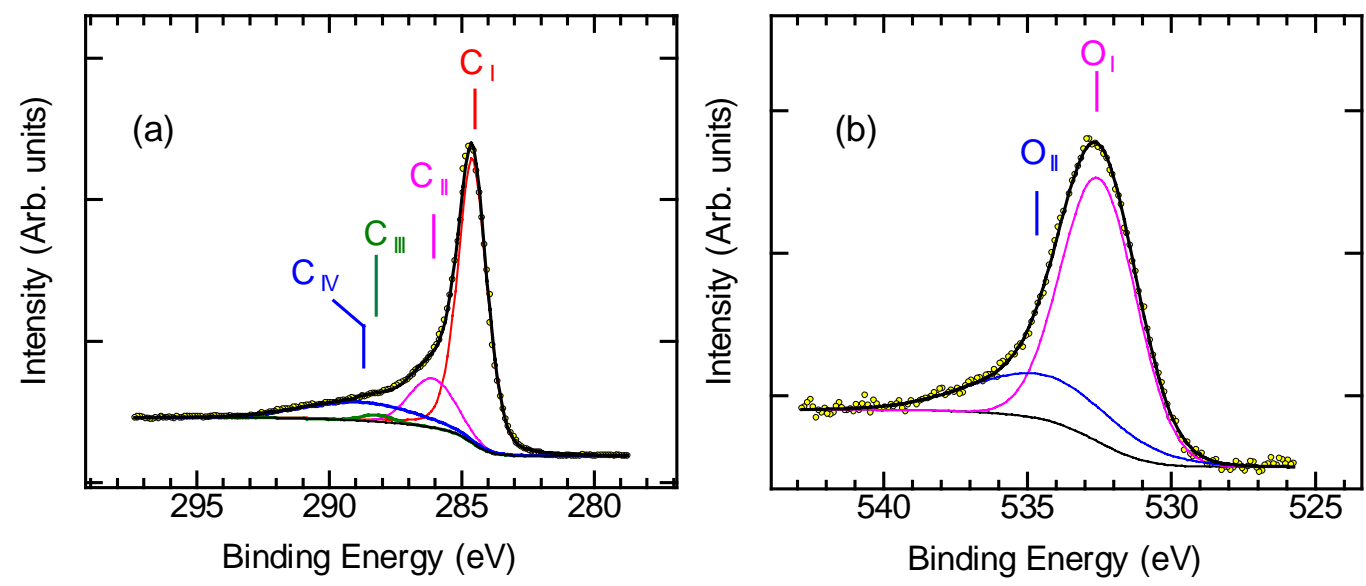

Figure S1. XP spectra of porous carbons. (a) C1s and (b) O1s of C[45]-5. Small circles and solid lines represent measured and calculated data, respectively.

\section{References}

(S1) Viswanathan, H.; Rooke, M. A.; Sherwood, P. M. A. Surf. Interface Anal. 1997, 25, 409. 